\title{
Cadherin superfamily genes: functions, genomic organization, and neurologic diversity
}

\author{
Takeshi Yagi ${ }^{1,3}$ and Masatoshi Takeichi ${ }^{2}$ \\ ${ }^{1}$ Laboratory of Neurobiology and Behavioral Genetics, National Institute for Physiological Sciences, Myodaiji, Okazaki \\ 444-8585, Japan; ${ }^{2}$ Cell and Developmental Biology, Graduate School of Biostudies, Kyoto University, Kitashirakawa, \\ Sakyo-ku, Kyoto 606-8502, Japan
}

To answer the question of how the highly sophisticated functions of the central nervous system (CNS) are born, we need to gain insight into the molecular mechanisms that generate an enormous number of diversified neurons and their specific interactions. The complex and highly organized neural networks in the CNS ultimately generate brain function, including innate and acquired behavior. Interestingly, the CNS is in part similar to the immune system, both are produced as complex, diversified, and well-organized networks from limited genomic information. The immune system promotes the recognition of the enormous battery of foreign antigens through the random diversification of T-cell receptors (TCR) and B-cell receptors (BCR) of the immunoglobulin superfamily by germ line rearrangement and/or somatic mutation. Analogous regulatory processes are not known for the CNS. However, recent studies of the cadherin superfamily have provided valuable insights into the generation of diversified and organized networks in the CNS.

A large number of cadherin superfamily genes have been identified to date, and most of them seem to be expressed in the CNS. In particular, primary cadherins (classic cadherins) were identified as synaptic components, and roles for them in neuronal circuitry, synaptic junction formation, and synaptic plasticity have been suggested (Suzuki et al. 1997; Tang et al. 1998; Honjo et al. 2000; Manabe et al. 2000; Tanaka et al. 2000). In addition, the expression of a novel cadherin, Arcadlin, was found to be up-regulated during activity-dependent synaptic plasticity (Yamagata et al. 1999). Moreover, a subfamily of the cadherin superfamily, CNR (cadherin-related neuronal receptor) proteins bound to tyrosine kinase Fyn, is localized in synaptic membrane (Kohmura et al. 1998). At least three protocadherin gene subfamilies including the CNRs are derived from an unusual genomic organization similar to that of $B C R$ and TCR gene clusters (Wu and Maniatis 1999; Sugino et al. 2000). These findings have interesting implications regarding

${ }^{3}$ Corresponding author.

E-MAIL yagi@nips.ac.jp; FAX 81-564-55-7741. the molecular events underlying the establishment of complex and organized networks of neuronal connections in the CNS, which may provide further insight into the processes giving rise to diverged brain functions in various species and individuals, as well as the molecular basis of psychociatic diseases.

\section{Cadherin superfamily: general molecular features}

At least 80 members of the cadherin superfamily have been shown to be expressed within a single mammalian species; these members include classic cadherins, desmogleins, desmocollins, protocadherins, CNRs, Fats, seven-pass transmembrane cadherins, and Ret tyrosine kinase (Fig. 1). All members of the cadherin superfamily are transmembrane proteins, with some exceptions, and are characterized by a unique domain, called cadherin motif or EC domain, containing the negatively charged DXD, DRE, and DXNDNAPXF sequence motifs, which are involved in $\mathrm{Ca}^{2+}$ binding (Takeichi 1990). The EC domains are tandemly repeated in the extracellular segment of all of the cadherin superfamily molecules, and the number of the EC domains varies considerably with the members. Although the presence of the EC domains is the hallmark of this molecular family, the amino acid sequences of other parts, in particular, the cytoplasmic domain, significantly diverge among the members, suggesting that their functional diversification has occurred during evolution. In Drosophila, six cadherin superfamily members have thus far been identified, and the Caenorhabditis elegans genome database indicates that this species has $\sim 20$ genes of this superfamily. Interestingly, only 1 molecule, of the 20 C. elegans cadherins, was identified as the classic cadherin type.

\section{Classic cadherins and Fats}

The structure and function of classic and desmosomal cadherin subfamilies have been reviewed repeatedly (e.g., Provost and Rimm 1999; Steinberg and McNutt 1999; Troyanovsky 1999; Gumbiner 2000), and only a 


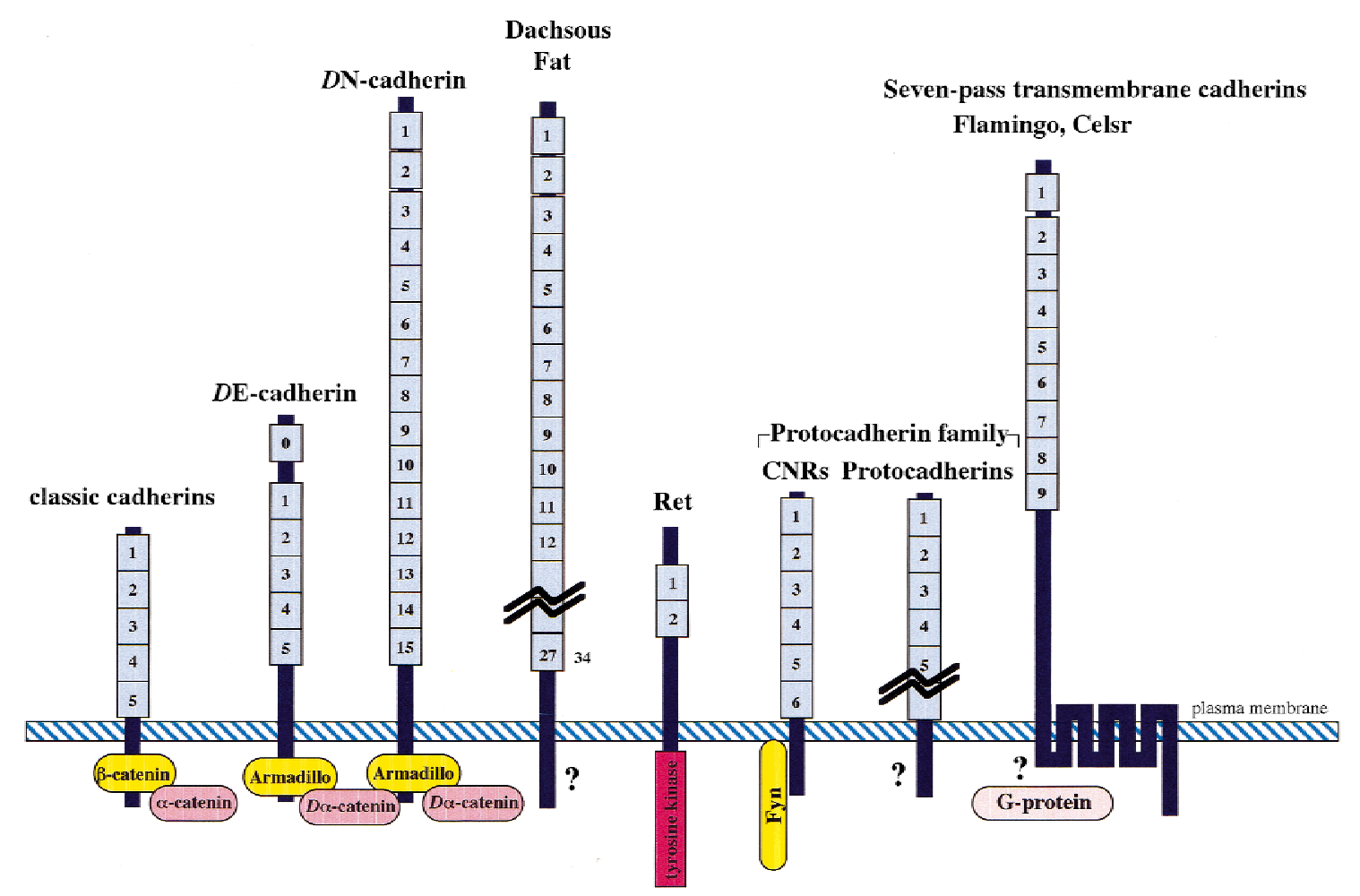

Figure 1. Schematic diagram of the molecular structure of the cadherin superfamily (blue) and their cytoplasmic interactors (yellow, pink). Classic cadherins have been primarily isolated as $\mathrm{Ca}^{2+}$-dependent cell adhesion molecules. Activity of cell adhesion is regulated by catenins bound to its cytoplasmic region. Approximately 80 members of the cadherin superfamily have been isolated. Most members are expressed in the CNS. CNRs bind to Fyn-tyrosine kinase in their cytoplasmic region. Interestingly, Drosophila cadherins have many EC repeats. The number of extracellular tandem repeats, ECs, varies.

brief summary of their properties is described here. These are homophilic adhesion molecules, and for their homophilic interactions, the EC domains play a crucial role. The intracellular domains are conserved among the members of each subfamily, and in the case of classic cadherins, they interact with catenin $\mathrm{p} 120^{\mathrm{ctn}}$ and $\beta$-catenin at different portions of the cytoplasmic domain. The latter binds to $\alpha$-catenin, and this molecular complex further associates with vinculin and other cytoskeletal proteins, resulting in the organization of adherens junction, or zonula adherens in polarized epithelial cells.

Related molecules have been identified in invertebrates. However, the structural organization of vertebrate classic cadherins is not entirely conserved in the invertebrate species (Oda and Tsukita 1999). For example, although Drosophila DE- and DN-cadherins are similar to vertebrate classic cadherins in respect to their binding ability to $\beta$-catenin (Armadillo) at the cytoplasmic domain, their extracellular domains are considerably divergent. Drosophila cadherins have more EC domains than the vertebrate cadherins, and also have an insertion of distinctive sequences between the last EC and transmembrane domains, which include a cysteinerich segment, and a laminin A-like domain (Iwai et al. 1997). Despite such differences, their function as homophilic adhesion molecules appears to be homologous to that of vertebrate classic cadherins (Tepass 1999). DEcadherin is expressed predominantly in epithelial tissues, and $D E$-cadherin mutations impair dynamic cell arrangement and rearrangement during oogenesis and embryogenesis. $D \mathrm{~N}$-cadherin mutations result in either embryonic lethality or uncoordinated locomotion in adults, and mutant embryos exhibit failures in axon patterning, including position shifts, defective bundling, and errors in directional migration of growth cones.

Fat and Dachsous organize another subfamlily, both contain large tandem arrays of EC domains (Fig. 1). Recessive lethal mutations in the $f t(f a t)$ gene cause hyperplastic, tumor-like overgrowth of larval imaginal discs in a cell-autonomous fashion, defects in differentiation and morphogenesis, and death during the pupal stage (Bryant et al. 1988; Mahoney et al. 1991). Mutations in the dachsous gene lead to defects in the morphogenesis of the thorax, legs, and wings during development of imaginal discs (Clark et al. 1995). However, molecular mechanisms underlying these phenotypes are poorly understood.

\section{Seven-pass transmembrane cadherins}

Recently, an unusual class of cadherins with a sevenpass transmembrane domain, which have similarity to a group of peptide hormone-binding, G-protein-coupled re- 
ceptors have been identified in both vertebrates and invertebrates. One of these cadherins, Drosophila Flamingo (Fmi), is located at cell-cell boundaries in a polarized fashion, and functions together with Frizzled (Fz) for the acquisition of proximal-distal polarity of wing hair cells. Mutants lacking Fmi exhibit disorganized planer polarity, and the polarized distribution of Fmi is influenced by alternating patterns of $\mathrm{Fz}$ expression (Usui et al. 1999|. Such actions of Fmi are likely mediated by a cytoplasmic signaling cascade distinct from that for classic cadherins. It is noteworthy that members of the secretin receptor family, which has similarity to Fmi at the transmembrane portion, have been demonstrated to increase the intracellular levels of cAMP and/or inositol phosphates upon ligand binding (for review, see Bockaert and Pin 1999). Mouse Celsr1 (Mcelsr) (Hadjantonakis et al. 1998), mFmi (Usui et al. 1999), and rat MEGF2 (Nakayama et al. 1998) were isolated from the CNS. These results suggest that seven-pass transmembrane cadherins may play roles in determining neuronal morphology through regulation of cell polarity.

\section{Protocadherin family}

Several groups have isolated cell surface molecules from the CNS in their search for additional cadherin-like molecules required for cell-cell interactions. These studies have yielded a large number of cadherin superfamily genes, identified as protocadherins $(P c)$ or CNRs (Table 1). Strikingly, several of these genes display unusual genomic structures reminiscent of that of $I g$ and TCR genes, as detailed in later sections.

Protocadherins were originally identified from rat brain by PCR method from rat brain (Sano et al. 1993). These molecules contain five or six repeats of the EC domain, but their cytoplasmic regions display no similarity to those of classic cadherins (Fig. 1). Members of this subfamily identified from different species are summarized in Table 1. An initial question about this group of molecules was whether they had cell adhesion activities, and rat Pc2 and Pc3 were found to induce aggregation of L cells when these molecules were exogeneously

Table 1. Protocadherin family

\begin{tabular}{lllll}
\hline Group & Human & Mouse & Rat & Others \\
\hline $\mathrm{A}$ & $P c d h \alpha$ & $C N R \mathrm{~s}$ & & \\
$\mathrm{~B}$ & $P c d h \beta$ & & $P c 3$ & \\
$\mathrm{C}$ & $P c d h \gamma$ & $P c 2 \mathrm{~B}$, & $P c 2, P c 4$, & \\
& & $P c 2 \mathrm{C}$ & $P c 5^{\star}, P c 6^{\star}$ & \\
$\mathrm{D}$ & $P c d h 42$ & & $P c 1$ & NFPC (Xenopus) \\
$\mathrm{E}$ & $P c d h 7$ & $B H-P c$ & & \\
$\mathrm{~F}$ & $P c d h 8$ & & $\operatorname{arcadlin}$ & \\
$\mathrm{G}$ & $P c d h 9$ & & & papc (Xenopus, \\
$\mathrm{H}$ & $P c d h 11$ & & & zebrafish) \\
$\mathrm{I}$ & & OL-Pc & & \\
$\mathrm{J}$ & & & & \\
\end{tabular}

\footnotetext{
${ }^{\star}$ Partial sequence
}

expressed (Sano et al. 1993). Chimeric molecules containing the extracellular domains of Pc2 and Pc3 fused to the cytoplasmic domain of E-cadherin display stronger homophilic cell adhesion activities than the original ones. These results indicate that the EC domains of protocadherins can undergo homophilic interactions, as found for those of classic cadherins, but the functions of the cytoplasmic domain are not identical between these two subfamilies. Molecules associated with the cytoplasmic region of Pc2 and Pc3 are yet to be found. Another member of the protocadherin group, Arcadlin, also shows homophilic adhesion activity (Yamagata et al. 1999).

In vivo functions of protocadherins have been studied during embyogenesis in zebrafish and Xenopus. NF-protocadherin (NFPC) in Xenopus, and paraxial protocadherin (PAPC) in Xenopus and zebrafish display regionspecific expression patterns during early embryognesis (Bradley et al. 1998; Kim et al. 1998; Yamamoto et al. 1998). NFPC, whose cytoplasmic domain is homologous to rat Pc1, is predominantly expressed within the deep, sensorial layer of the embryonic ectoderm and in a restricted group of cells in the neural folds, but is largely absent from the neural plate and surrounding placodal regions. Ectopic expression of NFPC in Xenopus embryos induces cell clustering within the embryonic ectoderm. In addition, expression of dominant-negative forms of NFPC, which contain deletions of the entire extracellular domain or cytoplasmic region, disrupt the integrity of the embryonic ectoderm. These results suggest that NFPC functions as a cell-adhesion molecule, but the mode of action should be distinct from that of classic cadherins, as mentioned above.

PAPC is expressed in the trunk mesoderm. Dominantnegative studies of PAPC demonstrated that PAPC is required for proper dorsal convergence movements during gastrulation. Furthermore, the floating head homeobox gene down-regulates the expression of PAPC. These data suggest that PAPC, in conjunction with the transcription factors such as homeobox proteins, executes morphogenetic cell movements during gastrulation (Yamamoto et al. 1998). Thus, these dominant-negative analyses demonstrate that the role of protocadherins is to control morphogenetic cell movement. Identification of cytoplasmic molecules interacting with each protocadherin molecule will greatly facilitate elucidation of their roles in such embryonic processes.

\section{CNRs associated with Fyn tyrosine kinase}

Another group of protocadherin-type molecules, designated as CNR, has been identified in the CNS through the yeast two-hybrid system approach using Fyn tyrosine kinase (Kohmura et al. 1998). Fyn is crucial for normal brain organization and function. Mice lacking Fyn exhibit behavioral abnormalities, and also display electrophysiological deficits in induction of LTP in the excitatory synapses and the GABAergic synaptic response, as well as morphological abnormalities during the migration of neurons and formation of dendrites (for review, 
see Yagi 1999). In neurons, Fyn is enriched in nerve growth cone membranes (Bare et al. 1993; Bixby and Jhabvala 1993) and the postsynaptic density fraction (Grant et al. 1992). The function of CNR cadherins could be coupled with these activities of Fyn.

CNR cadherins contain six EC domains, similar to other protocadherins, but have a distinct cytoplasmic domain that interacts with Fyn. Whereas the similarity of each CNR at the amino acid level varies from $53 \%$ to $80 \%$, specific motifs are well conserved. These include the RGD motif, which is primarily found in most of the ligands for integrins, the characteristic cysteine repeats in the transmembrane and cytoplasmic domains, and PXXP motifs, which bind to the SH3 domain. Interestingly, 152 amino acids at the carboxy-terminal tail are identical in all of the CNR cadherins. The cytoplasmic domain bears no similarity to any other proteins in the database. CNR cadherins exhibit some features distinct from classic cadherins and other protocadherins. When full-length CNR1 proteins were expressed in $\mathrm{L}$ and Neuro 2A cells, they were concentrated in the endoplasmic reticulum and Golgi with very few being transported into the plasma membrane, and hence their homophilicbinding activities were undetectable. Nevertheless, synaptic membrane localization of CNR proteins was found in the brain by immunohistochemical analyses at the electron microscope level. The mechanisms for the localization of CNR proteins to the plasma membrane in vivo, and the failure of this process in vitro remain to be elucidated. Interestingly, only the extracellular domain of CNR1 could be secreted from the L and HEK293 cells (Senzaki et al. 1999).

\section{Localization and functions of cadherin superfamily proteins in synapses}

Neurons communicate with each other via synapses. The synapses have a dual function, physiological and adhesive. Concerning the latter function, little is known about its molecular basis. Classic cadherins and associated catenins have been found in synapses (Yamagata et al. 1995; Fannon and Colman 1996; Uchida et al. 1996). Interestingly, the cadherin-catenin complexes are not present in the active zone, but are localized in areas bordering this zone (Fig. 2). In these regions, they exhibit a symmetrical distribution over the pre- and postsynaptic plasma membrane (Uchida et al. 1996). Moreover, it has been discovered that multiple classic cadherins are differentially expressed in the brain, and specific cadherin expression occurs in the process of delineating restricted neural circuits (Suzuki et al. 1997; Inoue et al. 1998). Because each of these classic cadherins has selective binding activities, they could function as a kind of lockand-key component for regulating specific interneuronal connections, as hypothesized by Sperry (1963).

As mentioned above, CNRs are also localized in synaptic junctions, forming a complex with Fyn, suggesting that they may play another role in establishing neuronal connections or in signal transduction at the synaptic membrane. However, these proteins appear to be local-
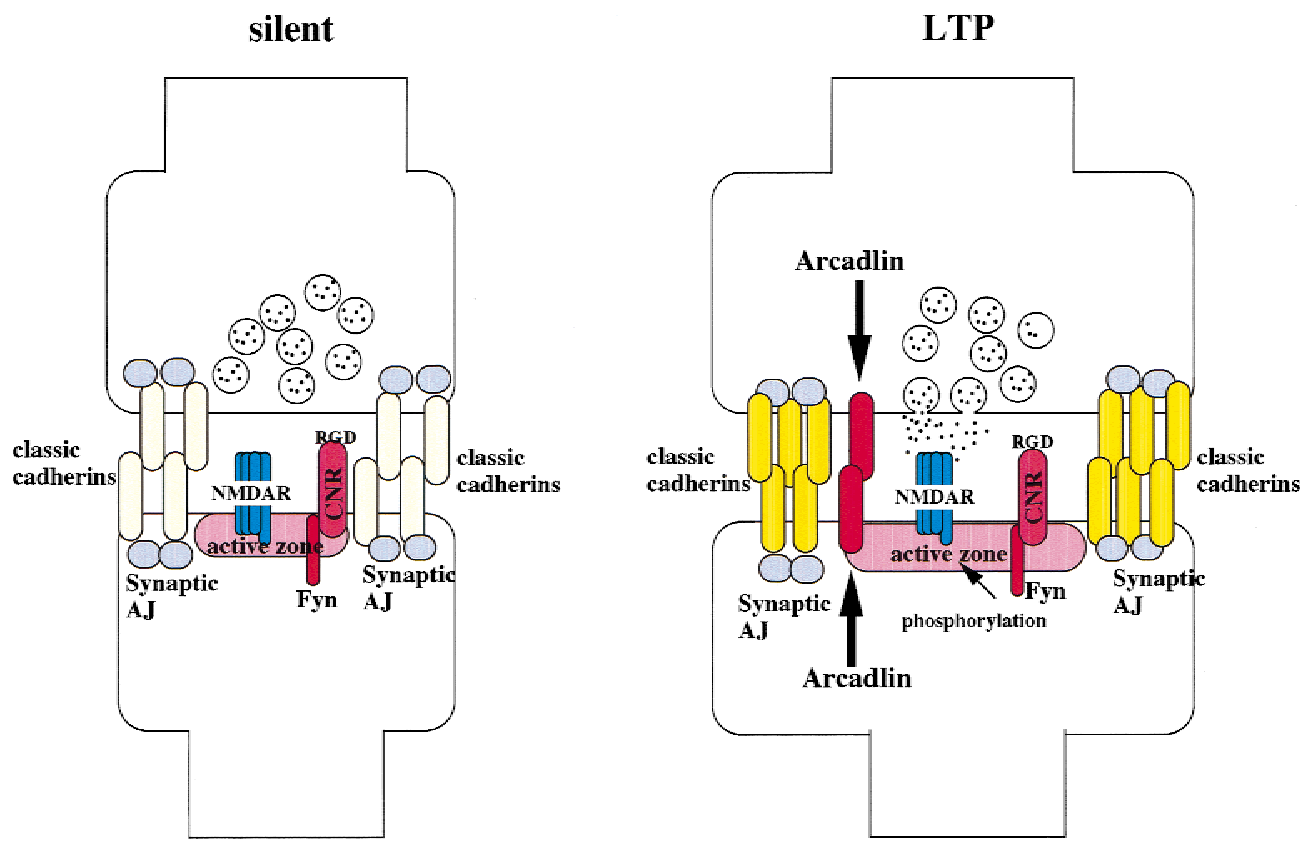

Figure 2. Schematic diagrams of cadherin superfamily proteins in the silent and LTP sypapses. Classic cadherins (ivory, yellow) and catenins (purple) are localized in synaptic adherence junction (AJ). Proteins of the CNR family are likely localized at the active zone. CNRs are associated with Fyn-tyrosine kinase. Fyn tyrosine-phosphorylates the NR2A and NR2B subunits of the NMDA receptor complex. During synaptic activation, Fyn is up-regulated, but no direct evidence has been presented supporting a role for CNRs in LTP. In parallel with presynaptic vesicle fusion, $\mathrm{N}$-cadherin is dispersed in the synaptic membrane. In addition, postsynaptic activation induces the dimerization of N-cadherin. At induction of synaptic LTP, Arcadlin is increased in the activated synapse. 
ized mainly in the active zone of small and probably immature synapses (Kohmura et al. 1998). CNR mRNAs are expressed in various regions of the brain, including the neocortex, hippocampus, cerebellum, and olfactory bulb. Furthermore, different neurons express distinct sets of CNR genes. These properties indicate that CNRs may play a role in the formation of specific neural connections and local circuits in the CNS. OL-Pc expression is also restricted to a subset of functionally related brain nuclei and regions such as the nuclei in the main olfactory system (Hirano et al. 1999a). Furthermore, Arcadlin was shown to colocalize with synaptophysin, a presynaptic marker. Together, many of the protocadherins seem to be synaptic components, and thus individual neurons may be labeled by different combinations of cadherin superfamily proteins at synaptic sites. Their combinatory expressions could confer an enormous variation of adhesive affinities on neurons.

Physiological roles of cadherins in synapses are being investigated. Recent studies have revealed that protein structure and distribution of $\mathrm{N}$-cadherin are changed through synaptic physiology. In the presynaptic membrane, N-cadherin dispersion after presynaptic depolarization parallels the rapid expansion of the presynaptic membranes subsequent to massive vesicle fusion (Tanaka et al. 2000). Furthermore, N-cadherin acquires protease resistance and undergoes dimerization at least 2 hr after depolarization. These experiments suggest that $\mathrm{N}$-cadherin may function in the alteration of synaptic morphology coordinated with synaptic plasticity. Another study investigated the role of classic cadherins in LTP induction utilizing antibodies and a peptide containing a conserved extracellular tripeptide sequence. Its major conclusion states that a significant inhibition of LTP is observed when either molecule is present during the induction of LTP (Tang et al. 1998). More recently, LTP was found to be rather enhanced in the hippocampus of mice whose cadherin-11 had been mutated (Manabe et al. 2000), suggesting that this cadherin plays a role in confining synaptic plasticity to a limited range. These mutant mice showed reduced fear-related responses in behavior assays, supporting the idea that cadherin-11 modulates synaptic function. It was also shown that antibodies to cadherin-6B expressed in a subset of retinal neurons affected the distribution of PSD-95, a postsynaptic scaffold protein, in their neurites (Honjo et al. 2000). This finding suggests that cadherins are involved in structural organization of synaptic junctions.

With regard to protocadherins, arcadlin was identified as an immediate early gene, which responded to the induction of synaptic LTP. This protocadherin expression is rapidly and transiently induced in hippocampal granule cells by N-methyl-D-aspartate (NMDA)-dependent synaptic activity in LTP at both the mRNA and protein levels. Furthermore, treatment with Arcadlin antibody reduces excitatory postsynaptic potential amplitude and blocks LTP in hippocampal slices. These findings suggest that Arcadlin is a candidate molecule for activityinduced synaptic reorganization on long-term memory. It seems premature to integrate all of these independent findings into a coherent story for explaining cadherin functions in synapses; however, they strongly suggest that cadherins play significant and important roles in structural and functional organization of synapses.

\section{CNR proteins as Reelin receptors}

Another role of cadherin superfamily genes has been demonstrated by a recent study on the CNR group. A feature of this protocadherin family is the well-conserved EC1 domain among the eight CNR proteins (Kohmura et al. 1998). Intriguingly, the conserved EC1 domain of CNRs is able to bind to Reelin protein (Senzaki et al. 1999). Reelin, a large extracellular matrix protein, is generated from Cajal-Retzius neurons, and functions in the cortical layering and positioning of neurons (D'Arcangelo et al. 1995). CNRs are expressed in neurons of the cortical layer during development. Binding between CNR and Reelin is disrupted by the CR-50 monoclonal antibody, an inhibitory antibody for in vivo Reelin function (Ogawa et al. 1995), suggesting that CNRs are actual receptors for Reelin function. Recent studies have also revealed that the very low-density lipoprotein receptor (VLDLR) and apolipoprotein E receptor 2 (ApoER2), which can bind to mammalian Disabled 1 (mDab1) via their cytoplasmic tails, bind to Reelin, and are involved in Reelin-induced tyrosine phosphorylation of $\mathrm{mDab} 1$ (D'Arcangelo et al. 1999; Hiesberger et al. 1999). mDab1deficient mice develop a phenotype indistinguishable from that of the Reelin-minus mutant, reeler mice (Howell et al. 1997; Sheldon et al. 1997). mDab1 is tyrosine phosphorylated by members of the Src family, including Fyn. The phosphotyrosine level of primary-cultured cortical neurons is increased by exogenous Reelin. A monoclonal antibody, anti-RBD (Reelin-binding domain) which targets the CNR EC1 domain can efficiently block the induction of the tyrosine-phosphorylation level of mDab1 by Reelin, suggesting that CNRs, Fyn or Src family proteins, mDab1, and VLDLR or ApoER2 may form a receptor complex with exogenous Reelin. In addition, anti-RBD can inhibit the normal migration of cortical neurons in cultured aggregates (Senzaki et al. 1999). Thus, CNR cadherins are distinguished from others by this unusual feature for participating in heterophilic interactions with Reelin, albeit heterophilic-binding activity of cadherins was observed previously between the EC1 domain of E-cadherin and integrin $\alpha E \beta 7$ (Karecla et al. 1996). Reelin is known to participate in various neurologic processes. These include the development of the cortex (D'Arcangelo et al. 1995), its influence in branching neurites (Del Rio et al. 1997), its expression in GABAergic interneurons of adults (Pesold et al. 1998), and its decreased expression in the brains of schizophrenia patients (Imapagnatiello et al. 1998), suggesting that interaction between Reelin and CNRs may be significant in the arborization of neurites, the formation of synapses, as well as being a putative vulnerability factor in schizophrenia.

Evolutionary analysis with probes targeting the Reelin-binding EC1 region of CNRs has revealed that the 
number of detectable bands is strikingly different among terrestrial vertebrates. Approximately 20, 10, 5, and 2 bands are found in mammals, birds, reptiles, and amphibians, respectively (Senzaki et al. 1999). In contrast, one to three bands are commonly detected among these species by probing with the cytoplasmic constant region of the CNR genes. The number of stained bands representing the RBDs of $C N R$ genes gradually increased from amphibia to mammals in parallel with the transition from brain simplicity to complexity. Nevertheless, the cytoplasmic constant region (see below) remained unchanged among terrestrial vertebrates. In addition, the number of $C N R$ (Pcdh $\alpha$ genes containing the RGD sequence for interaction with Reelin are evolutionarily altered between mice and humans (i.e., 11 genes are present in mice, in contrast to only 3 in humans). In human CNR (Pcdh $\alpha$ family proteins, the RGD motif is changed to HGD, HRD, RGG, RED, or HRD. Whereas it remains to be established whether these altered sequences still possess Reelin-binding activity, it is tempting to speculate that their differential interactions with the Reelin protein may influence the layering and positioning of neurons in the human CNS.

\section{Genomic organization of cadherin superfamily genes}

Many of the cadherin superfamily genes have been mapped to specific human and mouse chromosomes (Table 2). Nearly all cadherin superfamily genes are tightly linked to each other and several have been mapped to human chromosomes 5p14-15, 5q13-15, 5q31-32, 13q14.3-21.1, 16q22.1, 16q24.1, and 18q12.1. The genomic DNA structures are divided into two large groups, the classic and desmosomal cadherin group, and the CNRs $(P c d h \alpha), P c d h \beta, P c d h \gamma$, and $P c d h 8$ group (Fig. 3). The classic and desmosomal cadherins in general consist of 12-17 exons, and share a remarkable degree of conservation in intron positions. On the other hand, CNRs $(P c d h \alpha), P c d h \beta, P c d h \gamma$, and $P c d h 8$ genes contain long first exons that encode the extracellular domain $(\mathrm{EC})$, the transmembrane region $(\mathrm{T})$, and a part of the cytoplasmic tail (CP). The first exons of all of these genes with the exception of $P c d h \beta$ are linked by small exons, which encode the remainder of the cytoplasmic region. These data suggest that evolutionary diversification of cadherin superfamily genes may have been generated through gene duplication, reverse transcription to generate such large exons, and gene translocation. In addition, the protein structures and genomic structures of cadherin superfamily genes in Drosophila are very different from those of vertebrates, in spite of their similar functions for cell-cell adhesion and interactions.

\section{Genomic structures of the CNR subfamily}

A striking feature of the eight mouse CNR cDNAs is that the nucleotide sequences encoding the amino-terminal and transmembrane domains of each CNR are similar but distinct, whereas the nucleotide sequences encoding the carboxy-terminal cytoplasmic domain are completely identical (Kohmura et al. 1998). It has become apparent that the genomic organization of the CNR group ( $P c d h \alpha$ in human) contains similarities to that of Ig and TCR gene clusters (Wu and Maniatis 1999; Sugino et al. 2000). The amino-terminal extracellular, transmembrane domains, and part of the cytoplasmic tail of each CNR protein are encoded by a distinct and unusually large first exon; these large exons of CNR proteins are organized in a tandem array in the chromosome. In contrast, the carboxy-terminal cytoplasmic domain of each CNR protein is identical, and is encoded by three small exons located downstream from the cluster of amino-terminal exons. Wu and Maniatis (1999) have designated the tandemly clustered amino-terminal regions of the large exons as the variable region, and the commonly used three exons from the carboxyl terminus as the constant region. By direct R-banding FISH analysis, the CNR gene cluster has been localized to the $5 \mathrm{q} 31.1$ band of human chromosome 5 and to the R-positive C-band in mouse chromosome 18 (Sugino et al. 2000).

CNR genes have been found to give rise to three alternative transcripts (Sugino et al. 2000). Each single variable exon can potentially be connected to at least three different carboxy-terminal tails, comparable with class switching in the immunoglobulin heavy chain (Fig. 4). Additional features including conserved nucleotide sequence and gene organization in the CNR $(P c d h \alpha)$ gene cluster between mice and humans have been discovered (Fig. 3B). The amino acid sequences from the constant region are identical between mice and humans. Conserved amino acid sequences and orthologous gene order in the variable regions of the $C N R(P c d h \alpha)$ gene cluster between mice and humans have also been identified. However, pseudogenes are distinct between mice and humans. In particular, in humans, CNR3 is altered into a pseudogene, whereas in mice, $P c d h \alpha 8, P c d h \alpha 9$, and Pcdh $\alpha 12$ have been found to be pseudogenes. Thirteen actual genes have been identified in mice, and 15 have been identified in humans.

\section{Organization of other Pcdh gene clusters}

Comparison of the publicly available data from the human genome project with mouse CNR cDNA sequences has revealed 52 human cadherin-like genes organized into three tandem gene clusters within an $\sim 700-\mathrm{kb}$ stretch of the human chromosome 5q31 region (Wu and Maniatis 1999|. The first gene cluster was described above as a human CNR (Pcdh $\alpha)$ gene. The other gene clusters include $P c d h \beta$, which contains at least 15 genes plus 2 pseudogenes, the DNA sequences of which are similar to that of the rat Pc3 cDNA (Sago et al. 1995); and $P c d h y$, which is composed of 22 genes plus 1 pseudogene, the DNA sequences of which are similar to that of the rat $P c 2, P c d h 4(P c 2 B)$, and mouse $P c 2 C$ cDNAs (Sano et al. 1993; Obata et al. 1998; Hirano et al. 1999b).

In the $P c d h \beta$ gene cluster, each DNA repeat unit corresponds to a single variable region exon encoding the 
Cadhedrin superfamily

Table 2. Molecular features of cadherin superfamily

\begin{tabular}{|c|c|c|c|c|}
\hline \multirow[b]{2}{*}{ Gene } & \multirow{2}{*}{$\begin{array}{c}\text { No. of EC } \\
\text { domains }\end{array}$} & \multicolumn{2}{|c|}{ Chromosome } & \multirow[b]{2}{*}{ Comments } \\
\hline & & mouse & human & \\
\hline \multicolumn{5}{|l|}{ Classic cadherin } \\
\hline CDH1 (E-cadherin) & 5 & $8(53.3)$ & $16 q 22.1$ & \\
\hline $\mathrm{CDH} 2$ (N-cadherin) & 5 & $18(6.0)$ & $18 \mathrm{q} 12.1$ & \\
\hline CDH3 (P-cadherin) & 5 & $8(53.3)$ & $16 \mathrm{q} 22$ & \\
\hline CDH4 (R-cadherin) & 5 & $2(106.0)$ & $20 \mathrm{q} 13.3$ & \\
\hline CDH5 (VE-cadherin) & 5 & $8(51.0)$ & $16 \mathrm{q} 22.1$ & \\
\hline CDH6 (K-cadherin) & 5 & N.D. ${ }^{\mathrm{a}}$ & 5p14-p15.1 & \\
\hline $\mathrm{CDH7}$ & 5 & 1 & $18 \mathrm{q} 22-\mathrm{q} 23$ & \\
\hline $\mathrm{CDH8}$ & 5 & $8(46.5)$ & $16 \mathrm{q} 22.1$ & \\
\hline CDH9 (T1-cadherin) & 5 & N.D. & N.D. & \\
\hline CDH10 (T2-cadherin) & 5 & $15(9.0)$ & $5 \mathrm{p} 14-\mathrm{p} 13$ & \\
\hline CDH11 (OB-cadherin) & 5 & $8(46.5)$ & $16 \mathrm{q} 22.1$ & \\
\hline CDH12 (N-cadherin2) & 5 & $15(9.0)$ & 5p13-p14 & \\
\hline $\mathrm{CDH} 12 \mathrm{P}$ & & N.D. & $5 \mathrm{q} 13$ & pseudogene \\
\hline CDH13 (H-cadherin) & 5 & $8(64.0)$ & $16 \mathrm{q} 24.2-\mathrm{q} 24.3$ & \\
\hline $\mathrm{CDH} 14$ & 5 & 2 (rat) & N.D. & \\
\hline CDH15 (M-cadherin) & 5 & $8(67.0)$ & $16 \mathrm{q} 24.3$ & \\
\hline CDH16 (KSP-cadherin) & 5 & $8(50.0)$ & $16 \mathrm{q} 21-\mathrm{q} 22$ & \\
\hline CDH17 (LI-cadherin) & 5 & N.D. & 8q22.2-q22.3 & \\
\hline CDH18 & 5 & N.D. & $5 \mathrm{p} 15.1-\mathrm{p} 15.2$ & \\
\hline CDH19 (FIB1) ${ }^{\mathrm{b}}$ & 5 & N.D. & N.D. & \\
\hline CDH2O (FIB2) ${ }^{\mathrm{b}}$ & 5 & N.D. & N.D. & \\
\hline CDH21 (FIB3) ${ }^{\mathrm{b}}$ & 5 & N.D. & N.D. & \\
\hline CDH22 & 5 & N.D. & N.D. & \\
\hline PB-cadherin & 5 & N.D. & N.D. & \\
\hline EY-cadherin & 5 & N.D. & N.D. & \\
\hline \multicolumn{5}{|l|}{ Desmosomal cadherin } \\
\hline DSG1 & 4 & N.D. & $18 \mathrm{q} 12.1$ & \\
\hline DSG2 & 4 & N.D. & $18 \mathrm{q} 12.1$ & \\
\hline DSG3 & 4 & N.D. & $18 \mathrm{q} 12.1$ & \\
\hline DSC1 & 4 & N.D. & $18 \mathrm{q} 12.1$ & \\
\hline DSC2 & 4 & N.D. & $18 \mathrm{q} 12.1$ & \\
\hline DSC3 & 4 & N.D. & $18 \mathrm{q} 12.1$ & \\
\hline \multicolumn{5}{|l|}{ Protocadherin family } \\
\hline CNRs & 6 & 18 (C-band) & $5 \mathrm{q} 31.1$ & 13 clustered genes \\
\hline$P c d h \alpha$ & 6 & & $5 \mathrm{q} 31.1$ & 15 clustered genes \\
\hline$P c d h \beta$ & 6 & $18(17.0)$ & $5 q 31-32$ & 15 clustered genes \\
\hline Pcdhy & 7 & $18(18.0)$ & $5 \mathrm{q} 32$ & 22 clustered genes \\
\hline Pcdh7 (BH-pc) & 7 & N.D. & 4 p15 & NFPC of Xenopus \\
\hline Pcdh 8 & 6 & $14(43.0)$ & $13 \mathrm{q} 14.3-\mathrm{q} 21.1$ & arcadlin in rat \\
\hline Pcdh9 & 6 & $14(44.0)$ & $13 \mathrm{q} 14.3-\mathrm{q} 21.1$ & \\
\hline Pcdh11 & 7 & N.D. & $\mathrm{Xq} 21.3$ & \\
\hline$O L-p c$ & 6 & N.D. & N.D. & \\
\hline papc & 6 & N.D. & N.D. & Xenopus and zebrafish \\
\hline \multicolumn{5}{|c|}{ Cadherin EGF LAG seven-pass G-type receptor } \\
\hline Celsr 1 & 9 & $15(49.0)$ & $22 \mathrm{p} 13.31$ & \\
\hline$M E G F 2$ & 9 & N.D. & N.D. & rat \\
\hline mFmil & 9 & N.D. & N.D. & mouse Flamingol \\
\hline \multicolumn{5}{|l|}{ Tyrosine kinase } \\
\hline ret & 1 & $6(53.2)$ & $10 \mathrm{q} 11.2$ & \\
\hline \multicolumn{5}{|l|}{ Tumor suppressor } \\
\hline$F A T$ & 34 & N.D. & $4 q 34-q 35$ & \\
\hline$F A T 2 / M E G F 2$ & 34 & N.D. & $5 q 32-q 33$ & \\
\hline \multicolumn{5}{|l|}{ Drosophila cadherin } \\
\hline DN-cadherin & 15 & & & \\
\hline DE-cadherin & 5 & & & \\
\hline fat & 34 & & & \\
\hline dachsous & 27 & & & \\
\hline fmi & 9 & & & \\
\hline
\end{tabular}

a (N.D.) Not determined

${ }^{b}$ (FIB) Fibroblast cadherin 


\section{A. Linked cadherin genes (classic and desmosome cadherins)}

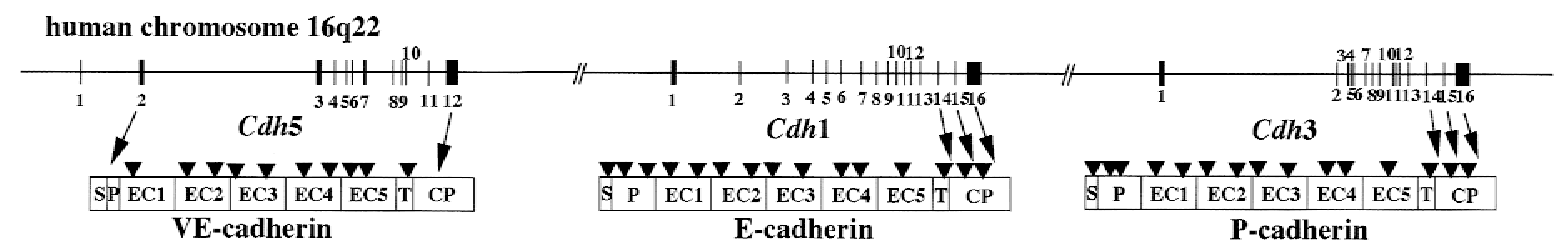

B. Clustered cadherin genes

mouse $C N R$ gene cluster

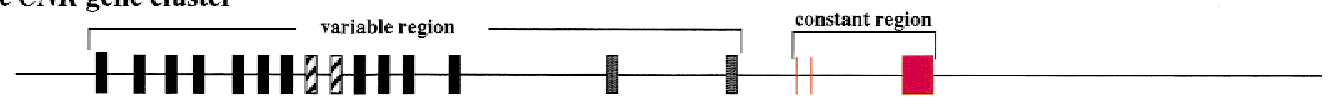

$P c d h \propto$ (human $C N R$ ) gene cluster

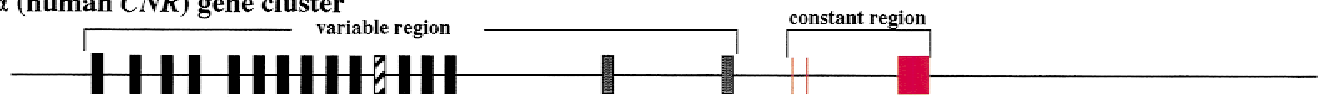

human $P c d h \gamma$ gene cluster

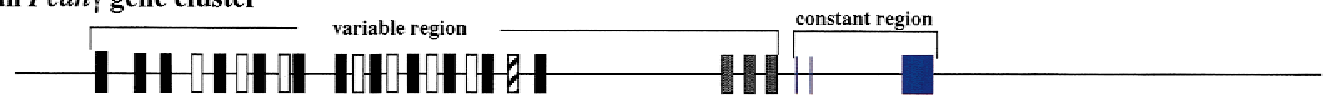

human $P c d h \beta$ gene cluster

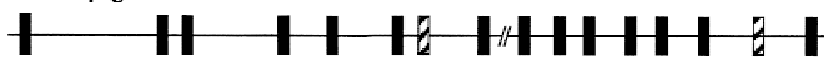

human chromosome 13q14.3-q21.1

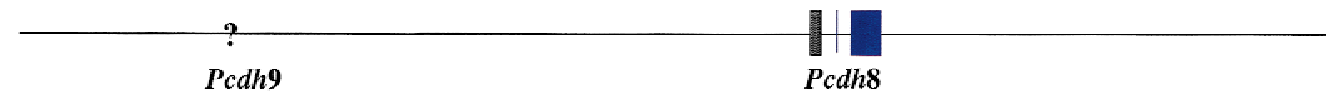

Figure 3. Genes of the cadherin superfamily are closely linked in the chromosomes. (A) For example, in human chromosome 16q22, Cdh5 (VE-cadherin), Cdh1 (E-cadherin), and Cdh3 (P-cadherin) genes are tightly linked. Each gene is derived from 12 to 16 exons. The cytoplasmic region of VE-cadherin is derived from one exon, but E- and P-cadherins from three exons. However, the positions of exon-intron junctions in mRNA of classic cadherins are conserved, but not always equal. $(B)$ Striking gene organizations similar to that of $I g$ and TCR genes are observed in the CNRs $(P c d h \alpha), P c d h \beta$, and $P c d h \gamma$ genes. CNRs $(P c d h \alpha)$ and $P c d h \gamma$ genes are separated into two genomic regions, tandemly clustered large exons in the variable region and commonly used exons in the constant region. Shadow boxes are pseudogenes. Pseudogenes of CNRs $(P c d h \alpha)$ are different between mouse and human. For example, the mouse CNR3 gene is a pseudogene in humans. Interestingly, the mRNA of Pcdh8 in human chromosome 13 is derived from a large exon at the $5^{\prime}$ region and two small exons at the $3^{\prime}$ region of the gene, similar to those of the CNRs (Pcdh $\left.\alpha\right)$ and Pcdhy genes. Because another Pcdh9 gene is tightly linked to Pcdh8, there is a possible gene cluster in human chromosome 13 .

extracellular, transmembrane, and cytoplasmic domains. Furthermore, no constant regions have been detected in $P c d h \beta$ although each exon has a consensus $5^{\prime}$ splice site sequence. This finding suggests that these exons may be spliced to a downstream constant region. The encoded proteins are similar to $\operatorname{CNR}(\operatorname{Pcdh} \alpha)$ but have many distinctive features, such as the presence of common histidine residues near the carboxyl terminus of EC1, which are not found in CNR (Pcdh $\alpha)$ and Pcdhy genes.

The amino-terminal extracellular, transmembrane, and partial cytoplasmic domains in the Pcdhy gene cluster are similar to those of CNR (Pcdh $\alpha)$ and $P c d h \beta$. As seen in the CNR $(P c d h \alpha)$ cluster, each exon is separately joined to a common carboxy-terminal cytoplasmic domain, which is encoded by three small constant region exons. Although the sequences of constant regions of CNR (Pcdh $\alpha)$ and Pcdhy do not share significant sequence homology, a lysine-rich motif is located at a similar position in both. Furthermore, exons 1 and 2 in the constant regions of CNR $(P c d h \alpha)$ and Pcdh $\gamma$ are of the same length, and $66 \%$ and $42 \%$ identical in DNA sequence, respectively. However, the corresponding amino acid sequences are only $20 \%$ identical, and Pcdh $\gamma$ does not contain the two corresponding PXXP motifs present in this region of CNR $(\operatorname{Pcdh} \alpha)$. The genomic structures of Pcdh8 (Strehl et al. 1998) and arcadlin are similar to those of CNR (Pcdh $\alpha)$ and Pcdhy clusters.

\section{Potential neurologic roles of cadherin superfamily gene clusters}

The above pattern of protocadherins/CNRs genomic organization characterized by multiple variable exons and the single constant exon alludes to the possibility of gene rearrangement in the brain. The first indication of this hypothesis came from studies of mutant mice deficient for components of the enzymatic machinery essential for the DNA rearrangements that give rise to the genes for mature $I g$ and TCR. These mutant mice, deficient for 


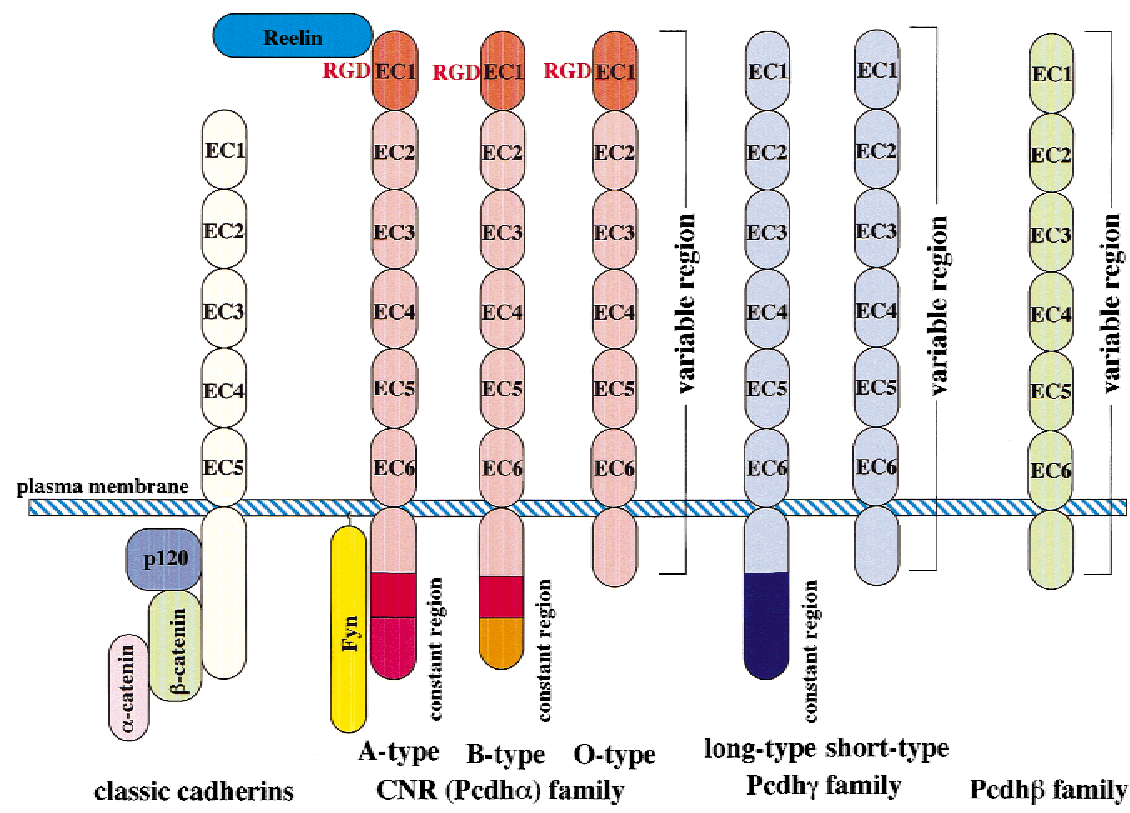

Figure 4. Schematic diagram of the molecular structure of classic cadherins, CNRs $(\operatorname{Pcdh} \alpha), \operatorname{Pcdh} \beta$, and Pcdh $\gamma$ and their binding proteins. CNRs $(\operatorname{Pcdh} \alpha), \operatorname{Pcdh} \beta$, and Pcdh $\gamma$ are derived from their gene clusters in chromosomes. CNRs and Pcdh $\gamma$ are expressed by linking their variable exon and constant exons. At least three and two cytoplasmic variants are observed in the CNRs and Pcdh $\gamma$, respectively. The Reelinbinding activity has been shown only in the mouse CNR family. either DNA ligase IV or its dimerization partner XRCC4, were found to exhibit a striking increase in the death of very young neurons and neuroblasts (Gao et al. 1998). Interestingly, this cell death correlated with the differentiational stage of neurogenesis. Futhermore, in the developing cortex of embryonic day 15 mice, the expression pattern of transcripts derived from the multiple variable exons and the constant exon from the CNR cluster correlates to the spatial patterns of cell death. These results provide further indications of gene rearrangement in CNR gene clusters. The interactive stage between Reelin and CNR proteins occured after the cell death stage of these mutants, which led to a positive selection model for neurons expressing CNR proteins by Reelin (Senzaki et al. 1999; Fig. 5). In addition, there are possibilities for gene rearrangement in the other clustered cadherin genes.

The studies of the cadherin superfamily in the CNS also provide us with a framework for hypotheses addressing the molecular basis of brain diseases, in particular, schizophrenia. Schizophrenia affects $\sim 1 \%$ of the population (McGue et al. 1983) with a severe chronic disorder characterized by social withdrawal, illogical thinking, delusions, and hallucinations, and is accompanied by various degrees of social, emotional, and behavioral disruption. Family, twin, and adoption studies have shown that genetic factors markedly increase the risk for schizophrenia (Bertelsen 1985; Gershon et al. 1988; Kendler 1988; Gottesman and Bertesen 1989). The transmission of schizophrenia is unlikely to be caused by a single gene manifesting a very large effect $\left(\mathrm{O}^{\prime}\right.$ Rourke et al. 1982). Polygenic or oligogenic multifactorial inheritance (Tsuang et al. 1991) probably accounts for most of the genetic susceptibility (Risch 1990a,b). By linkage analyses, several loci have been identified that confer increased susceptibility to schizophrenia. Comparisons between these linkages and gene loci of the cadherin su- perfamily have revealed that $5 \mathrm{p} 14.1-13.1$ of $C D H 6$, CDH10, CDH12, and CDH12P, 5q31 of Pcdh $\alpha$ (human CNRs), Pcdh $\beta$, and Pcdhy, 13q14 of Pcdh8 and Pcdh9, 18q12.1-12.3 of CDH2 (N-cadherin), 7, DSG1-3, and $D S C 1-3 ; 4 \mathrm{p} 15$ of $B H-P C$ map within potential regions underlying susceptibility to schizophrenia (Schwab et al. 1997; Riley et al. 1998; Barden and Morissette 1999; Crowe and Vieland 1999; Van Broeckhoven and Verheyen 1999|. These data prompt a cadherin hypothesis for schizophrenia in parallel with the previous dopamine and/or the glutamate hypotheses.

Thus, future functional analyses of the cadherin superfamily may reveal novel molecular mechanisms underlying psychociatic diseases. In addition, the observed diversity among animal species and differential somatic usage of the cadherin superfamily genes will provide insights into the diverged brain functions in various species and individuals.

\section{Conclusion}

Recent molecular studies of the cadherin superfamily, such as synaptic function, gene diversification, analogous mechanism to immune system, signaling cascades (linked to tyrosine kinase and extracellular Reelin), and tightly linked gene maps of susceptibility to psychociatic schizophrenia, leave us with an interesting impression to get insight into the molecular mechanism for building and regulating the neural networks in the brain. Moreover, most cadherin superfamily proteins are expressed in the CNS. The immune system is derived by diversification and interaction of the immunoglobulin superfamily. The CNS of another highly sophisticated system may be determined by the diversification and interaction of molecules including the cadherin superfamily. Thus, the story of cadherin superfamily initiated by specific cell adhesions will allow us to open a new 
Figure 5. Similarity between $C N R$ and TCR genes. (A) TCR genes are organized as a gene cluster, and their products are generated by DNA rearrangement and RNA splicing events. The functional proteins are translocated to the plasma membrane and form a protein complex with a nonreceptortype tyrosine kinase. The applicable TCR that makes a receptor complex with the CD8 or CD4 coreceptor is negatively and/ or positively selected by a major histocompatibility complex (MHC) class I or class II, respectively. Thus, diversity and regulation of TCR expression are required to establish diversity and ordered organization of the immune system. $(B)$ Analogously, multiple receptors of CNR proteins form a protein complex with Fyn, nonreceptor-type tyrosine kinase, and localize in the plasma membranes of developing neurons or synapses. The CNR genes also organize as a gene cluster. The organization of the gene cluster is similar to that of $I g$ and TCR genes and is divided into the variable and constant regions. During development of the cortex, the functional CNR proteins recognize extracellular Reelin proteins originated from the Cajal-Retzius cell. The CNR-positive neurons receive signals from Reelin and can contribute to normal layering and positioning. In addition, this signaling pathway is also used for regulating morphogenesis of neurons. Recent data revealed that VLDLR and ApoER2 also bind to Reelin, suggesting a possible model in which the CNR proteins form a receptor complex with these receptor molecules. Thus, there is an analogy of molecular features between TCR and CNR. Therefore diversity and regulation of the CNR expression may be required to establish diversity and ordered organization of the CNS.
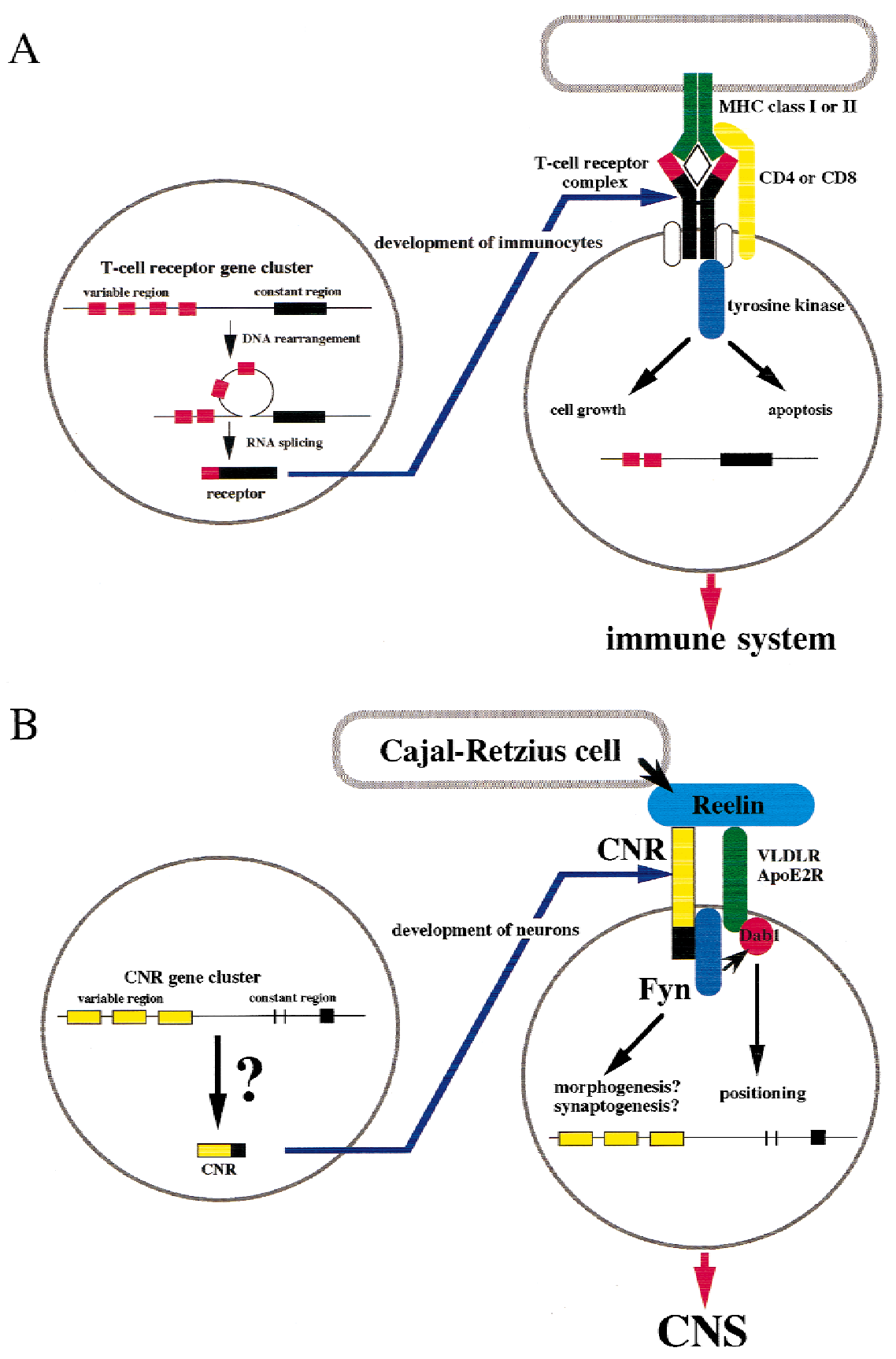

field on the neurologic molecular mechanisms in the CNS.

\section{Acknowledgments}

We thank Seiichi Takahashi, Shun Hamada, Kouji Senzaki and members of our laboratory for their stimulating comments, and Dr. Stefan Moisyadi (in U.H.) for critical reading. This work was supported by Grants-in-Aid from the Ministry of Education, Science, Sports, and Culture of Japan to T.Y. and M.T., and CREST (Core Research for Evolutional Science and Technology) of JST (Japan Science and Technology Corporation) to T.Y.

\section{References}

Barden, N. and J. Morissete. 1999. Chromosome 13 workshop report. Am. J. Med. Genet. 88: 260-262.

Bare, D.J., J.M. Lauder, M.B. Wilkie, and P.F. Maness. 1993. p59fyn in rat brain is localized in developing axonal tracts and subpopulations of adult neurons and glia. Oncogene 8: 1429-1436.

Bertelsen, A. 1985. Controversies and consistencies in psychiatric genetics. Acta. Psychiatr. Scand. Suppl. 319: 61-75.

Bixby, J.L. and P. Jhabvala. 1993. Tyrosine phosphorylation in early embryonic growth cones. J. Neurosci. 13: 3421-3432.

Bockaert, J. and J.P. Pin. 1999. Molecular tinkering of G proteincoupled receptors: An evolutionary success. EMBO $J$. 
18: $1723-1729$.

Bradley, R.S., A. Espeseth, and C. Kintner. 1998. NF-protocadherin, a novel member of the cadherin superfamily, is required for Xenopus ectodermal differentiation. Curr. Biol. 8: 325-334.

Bryant, P.J., B. Huettner, L.I. Held Jr., J. Ryerse, and J. Szidonya. 1988. Mutations at the fat locus interfere with cell proliferation control and epithelial morphogenesis in Drophiphila. Dev. Biol. 129: 541-554.

Clark, H.F., D. Brentrup, K. Schneitz, A. Bieber, C. Goodman, and M. Noll. 1995. Dachsous encodes a member of the cadherin superfamily that controls imaginal disc morphogenesis in Drosophila. Genes \& Dev. 9: 1530-1542.

Crowe, R.R. and V. Vieland. 1999. Report of the chromosome 5 workshop of the sixth world congress of psychiatric genetics. Am. J. Med. Genet. 88: 229-232.

D'Arcangelo, G., G.G. Miao, S.C. Chen, H.D. Soares, J.I. Morgan, and T. Curran. 1995. A protein related to extracellular matrix proteins deleted in the mouse mutant reeler. Nature 374: 719-723.

D'Arcangelo, G., R. Homayouni, L. Keshvara, D.S. Rice, M. Sheldon, and T. Curran. 1999. Reelin is a ligand for lipoprotein receptors. Neuron 24: 471-479.

Del Rio, J.A., B. Heimrich, V. Borrell, E. Forster, A. Drakew, S. Alcantara, K. Nakajima, T. Miyata, M. Ogawa, K. Mikoshiba et al. 1997. A role for Cajal-Retzius cells and reelin in the development of hippocampal connections. Nature 385: 7074.

Fannon, A.M. and D.R. Colman. 1996. A model for central synaptic junctional complex formation based on the differential adhesive specificities of cadherins. Neuron 17: 423-434.

Gao, Y., Y. Sun, K.M. Frank, P. Dikkes, Y. Fujiwara, K.J. Seidl, J.M. Sekiguchi, G.A. Rathbun, W. Swat, J. Wang et al. 1998. A critical role for DNA end-joining proteins in both lymphogenesis and neurogenesis. Cell 95: 891-902.

Gershon, E.S., L.E. DeLisi, J. Hauser, J.I. Nurnberger, M.E. Maxwell Jr., J. Schreiber, D. Dauphinais, C.W. Dingman 2d, and J.J. Guroff. 1988. A controlled family study of chronic psychoses: Schizophrenia and schizoaffective disorder. Arch. Gen. Psychiatry 45: 328-336.

Gottesman, I.I. and A. Bertelsen. 1989. Confirming unexpressed genotypes for schizophrenia: Risks in the offspring of Fischer's Danish identical and fraternal discordant twins. Arch. Gen. Psychiatry 46: 867-872.

Grant, S.G., T.J. O’Dell, K.A. Karl, P.L. Stein, P. Soriano, and E.R. Kandel. 1992. Impaired long-term potentiation, spatial learning, and hippocampal development in fyn mutant mice. Science 258: 1903-1910.

Gumbiner, B.M. 2000. Regulation of cadherin adhesive activity. J. Cell Biol. 148: 399-403.

Hadjantonakis, A.K., C.J. Formstone, and P.F.R. Little. 1998. MCelsrl is an evolutionarily conserved seven-pass transmembrane receptor and is expressed during mouse embryonic development. Mech. Dev. 78: 91-95.

Hiesberger, T., M. Trommsdorff, B.W. Howell, A. Goffinet, M.C. Mumby, J.A. Cooper, and J. Herz. 1999. Direct binding of Reelin to VLDL receptor and ApoE receptor 2 induces tyrosine phosphorylation of disabled-1 and modulates tau phosphorylation. Neuron 24: 481-489.

Hirano, S., Q. Yan, and S.T. Suzuki. 1999a. Expression of a novel protocadherin, OL-protocadherin, in a subset of functional systems of the developing mouse brain. J. Neurosci. 19: 9951005.

Hirano, S., T. Ono, Q. Yan, X. Wang, S. Sonta, and S.T. Suzuki. 1999b. Protocadherin 2C: A new member of the protocadherin 2 subfamily expressed in a redundant manner with
OL-protocadherin in the developing brain. Biochem. Biophys. Res. Commun. 260: 641-645.

Honjo, Y., S. Nakagawa, and M. Takeichi. 2000. Blockade of cadherin-6B activity perturbs the distribution of PSD-95 family proteins in retinal neurons. Genes Cells 5: 309-318.

Howell, B.W., R. Hawkes, P. Soriano, and J.A. Cooper. 1997. Neuronal position in the developing brain is regulated by mouse disabled-1. Nature 389: 733-737.

Impagnatiello, F., A.G.R. Guidotti, C. Pesold, Y. Dwivedi, H. Caruncho, M.G. Pisu, D.P. Uzunov, N.R. Smalheiser, J.M. Davis, G.N. Pandey et al. 1998. A decrease of reelin expression as a putative vulnerability factor in schizophrenia. Proc. Natl. Acad. Sci. 95: 15718-15723.

Inoue, T., T. Tanaka, S.C. Suzuki, and M. Takeichi. 1998. Cadherin-6 in the developing mouse brain: Expression along restricted connection systems and synaptic localization suggest a potential role in neuronal circuitry. Dev. Dynam. 211: 338-351.

Iwai, Y., T. Usui, S. Hirano, R. Steward, M. Takeichi, and T. Uemura. 1997. Axon patterning requires DN-cadherin, a novel neuronal adhesion receptor, in the Drosophila embryonic CNS. Neuron 19: 77-89.

Karecla, P.I., S.J. Green, S.J. Bowden, J. Coadwell, and P.J. Kilshaw. 1996. Identification of a binding site for integrin E7 in the $\mathrm{N}$-terminal domain of E-cadherin. J. Biol. Chem. 271: 30909-30915.

Kendler, K.S. 1988. Familial aggregation of schizophrenia and schizophrenia spectrum disorders. Evaluation of conflicting results. Arch. Gen. Psychiatry 45: 377-383.

Kim, S.H., A. Yamamoto, T. Bouwmeester, E. Agius, and E.M. Robertis. 1998. The role of paraxial protocadherin in selective adhesion and cell movements of the mesoderm during Xenopus gastrulation. Development 125: 4681-4690.

Kohmura, N., K. Senzaki, S. Hamada, N. Kai, R. Yasuda, M. Watanabe, H. Ishii, M. Yasuda, M. Mishina, and T. Yagi. 1998. Diversity revealed by a novel family of cadherins expressed in neurons at a synaptic complex. Neuron 20: 11371151.

Mahoney, P.A., U. Weber, P. Onofrechuk, H. Biessmann, P.J. Bryant, and C.S. Goodman. 1991. The fat tumor supressor gene in Drosophila encodes a novel member of the cadherin gene superfamily. Cell 67: 853-868.

Manabe, M., H. Togashi, N. Uchida, S.C. Suzuki, Y. Hayakawa, M. Yamamoto, H. Yoda, T. Miyakawa, M. Takeichi, and O. Chisaka. 2000. Loss of cadherin-11 adhesion receptor enhances plastic changes in hippocampal synapses and modifies Behavioral Responses. Mol. Cell. Neurosci. (in press).

McGue, M., I.I. Gottesman, and D.C. Rao. 1983. The transmission of schizophrenia under a multifactorial threshold model. Am. J. Hum. Genet. 35: 1161-1178.

Nakayama, M., D. Nakajima, T. Nagase, N. Nomura, N. Seki, and O. Ohara. 1998. Identification of high-molecular-weight proteins with multiple EGF-like motifs by motif-trap screening. Genomics 51: 27-34.

Obata, S., H. Sago, N. Mori, M. Davidson, T. St John, and S.T. Suzuki. 1998. A common protocadherin tail: Multiple protocadherins share the same sequence in their cytoplasmic domains and are expressed in different regions of brain. Cell Adhes. Commun. 6: 323-333.

Oda, H. and S. Tsukita. 1999. Nonchordate classic cadherins have a structurally and functionally unique domain that is absent from chordate classic cadherins. Dev. Biol. 216: 406422.

Ogawa, M., T. Miyata, K. Nakajima, K. Yagyu, M. Seike, K. Ikenaka, H. Yamamoto, and K. Mikoshiba. 1995. The reeler gene-associated antigen on Cajal-Retzius neurons is a crucial 
molecule for laminar organization of cortical neurons. Neuron 14: 899-912.

O'Rourke, D.H., I.I. Gottesman, B.K. Suarez, J. Rice, and T. Reich. 1982. Refutation of the general single-locus model for the etiology of schizophrenia. Am. J. Hum. Genet. 46: 222228.

Pesold, C., F. Impagnatiello, M.G. Pisu, D.P. Uzunov, E. Costa, A. Guidotti, and H.J. Caruncho. 1998. Reelin is preferentially expressed in neurons synthesizing gamma-aminobutyric acid in cortex and hippocampus of adult rats. Proc. Natl. Acad. Sci. 95: 3221-3226.

Provost, E. and D.L. Rimm. 1999. Controversies at the cytoplasmic face of the cadherin-based adhesion complex. Curr. Opin. Cell Biol. 11: 567-572.

Riley, B.P., M.W. Lin, M. Mogudi-Carter, T. Jenkins, R. Williamson, J.F. Powell, D. Collier, and R. Murray. 1998. Failure to exclude a possible schizophrenia susceptibility locus on chromosome 13q14.1-q32 in southern African Bantu-speaking families. Psychiatr. Genet. 8: 155-162.

Risch, N. 1990a. Linkage strategies for genetically complex traits. I. Multilocus models. Am. J. Hum. Genet. 46: $222-$ 228 .

- 1990b. Linkage strategies for genetically complex traits. II. The power of affected relative pairs. Am. J. Hum. Genet. 46: 229-241.

Sago, H., M. Kitagawa, S. Obata, N. Mori, S. Taketani, J.M. Rochelle, M.F. Seldin, M. Davidson, T. St John, and S.T. Suzuki. 1995. Nucleotide cloning, expression, and chromosomal localization of a novel cadherin-related protein, protocadherin-3. Genomics 29: 631-640.

Sano, K., H. Tanihara, R.L. Heimark, S. Obata, M. Davidson, T. St John, S. Taketani, and S. Suzuki. 1993. Protocadherins: A large family of cadherin-related molecules in central nervous system. EMBO T. 12: 2249-2256.

Schwab, S.G., G.N. Eckstein, J. Hallmayer, B. Lerer, M. Albus, M. Borrmann, D. Lichtermann, M.A. Ertl, W. Maier, and D.B. Wildenauer. 1997. Evidence suggestive of a locus on chromosome $5 \mathrm{q} 31$ contributing to susceptibility for schizophrenia in German and Israeli families by multipoint affected sib-pair linkage analysis. Mol. Psychiatry 2: 156-160.

Senzaki, K., M. Ogawa, and T. Yagi. 1999. Proteins of the CNR family are multiple receptors for Reelin. Cell 99: 635-647.

Sheldon, M., D.S. Rice, G. D'Arcangelo, H. Yoneshima, K. Nakajima, K. Mikoshiba, B.W. Howell, J.A. Cooper, D. Goldowitz, and T. Curran. 1997. Scrambler and yotari disrupt the disabled gene and produce a reeler-like phenotype in mice. Nature 389: 730-733.

Sperry, R.W. 1963. Chemoaffinity in the orderly growth of nerve fiber patterns and connections. Proc. Natl. Acad. Sci. 50: 703-710.

Steinberg, M.S. and P.M. McNutt. 1999. Cadherins and their connections: Adhesion junctions have broader functions. Curr. Opin. Cell Biol. 11: 554-560.

Strehl, S., K. Glatt, Q.M. Liu, H. Glatt, and M. Lalande. 1998. Characterization of two novel protocadherins (PCDH8 and $P C D H$ 9) localized on human chromosome 13 and mouse chromosome 14. Genomics 53: 81-89.

Sugino, H., S. Hamada, R. Yasuda, A. Tuji, Y. Matsuda, M. Fujita, and T. Yagi. 2000. Genomic organization of the family of CNR cadherin genes in mice and humans. Genomics 63: $75-87$.

Suzuki, S.C., T. Inoue, Y. Kimura, T. Tanaka, and M. Takeichi. 1997. Neuronal circuits are subdivided by differential expression of type-II classic cadherins in postnatal mouse brains. Mol. Cell. Neurosci. 9: 433-447.

Takeichi, M. 1990. Cadherins: A molecular family important in selective cell-cell adhesion. Annu. Rev. Biochem. 59: 237252.

Tanaka, H., W. Shan, G.R. Phillips, K. Arndt, O. Bozdagi, L. Shapiro, G.W. Huntley, D.L. Benson, and D.R. Colman. 2000. Molecular modification of $\mathrm{N}$-cadherin in response to synaptic activity. Neuron 25: 93-107.

Tang, L., C.P. Hung, and E.M. Schuman. 1998. A role for the cadherin family of cell adhesion molecules in hippocampal long-term potentiation. Neuron 20: 1165-1175.

Tepass, U. 1999. Genetic analysis of cadherin function in animal morphogenesis. Curr. Opin. Cell Biol. 11: 540-548.

Troyanovsky, S.M. 1999. Mechanism of cell-cell adhesion complex assembly. Curr. Opin. Cell Biol. 11: 561-566.

Tsuang, M.T., M.W. Gilbertson, and S.V. Faraone. 1991. The genetics of schizophrenia: Current knowledge and future directions. Schizophr. Res. 4: 157-171.

Uchida, N., Y. Honjyo, K.R. Johnson, M.J. Wheelock, and M. Takeichi. 1996. The catenin/cadherin adhesion system is localized in synaptic junctions bordering transmitter release zones. J. Cell Biol. 135: 767-779.

Usui, T., Y. Shima, Y. Shimada, S. Hirano, R.W. Burgess, T.L. Schwarz, M. Takeichi, and T. Uemura. 1999. Flamingo, a seven-pass transmembrane cadherin, regulates planar cell polarity under the control of Frizzled. Cell 98: 585-595.

Van Broeckhoven, C. and G. Verheyen. 1999. Report of the chromosome 18 workshop. Am. J. Med. Genet. 88: 263-270.

$\mathrm{Wu}, \mathrm{Q}$. and T. Maniatis. 1999. A striking organization of a large family of human neural cadherin-like cell adhesion genes. Cell 97: 779-790.

Yagi, T. 1999. Molecular mechanisms of Fyn-tyrosine kinase for regulating mammalian behaviors and ethanol sensitivity. Biochem. Pharmacol. 57: 845-850.

Yamagata, M. and J.R. Sanes. 1995. Lamina-specific cues guide outgrowth and arborization of retinal axons in the optic tectum. Development 121: 189-200.

Yamagata, K., K.I. Andreasson, H. Sugiura, E. Maru, M. Dominique, Y. Irie, N. Miki, Y. Hayashi, M. Yoshioka, K. Kaneko et al. 1999. Arcadlin is a neural activity-regulated cadherin involved in long term potentiation. J. Biol. Chem. 274: 19473-19479.

Yamamoto, A., S.L. Amacher, S.-H. Kim, D. Geissert, C.B. Kimmel, and E.M. De Robertis. 1998. Zebrafish paraxial protocadherin is a downstream target of spadetail involved in morphogenesis of gastrula mesoderm. Development 125: 3389-3397. 


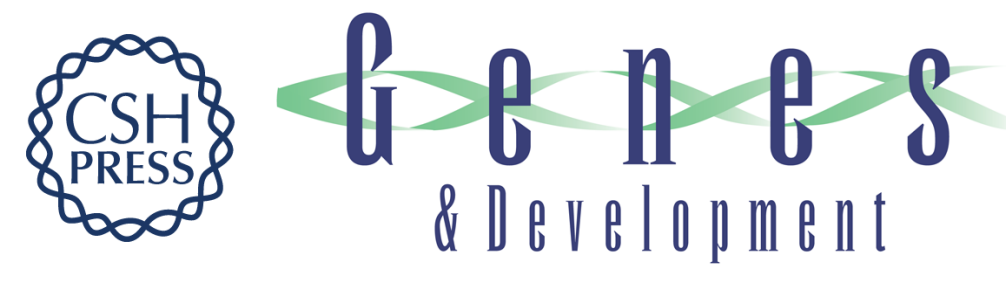

\section{Cadherin superfamily genes: functions, genomic organization, and neurologic diversity}

Takeshi Yagi and Masatoshi Takeichi

Genes Dev. 2000, 14:

Access the most recent version at doi:10.1101/gad.14.10.1169

References This article cites 67 articles, 15 of which can be accessed free at: http://genesdev.cshlp.org/content/14/10/1169.full.html\#ref-list-1

License

Email Alerting

Receive free email alerts when new articles cite this article - sign up in the box at the top Service right corner of the article or click here.

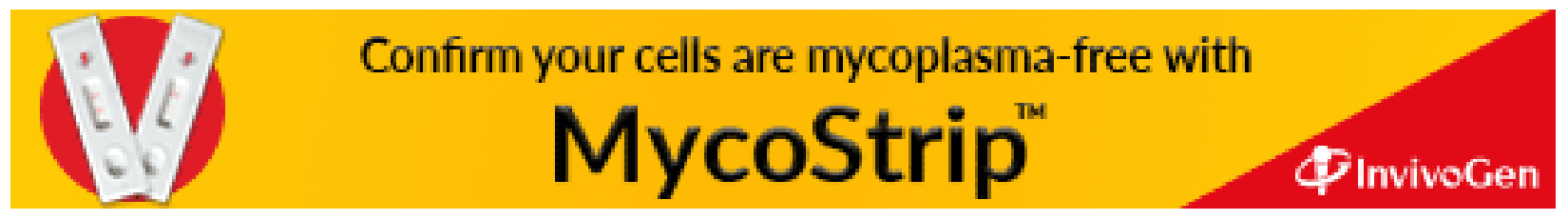

